\title{
Forum
}

\section{Classics at Lionheart Trust}

\author{
Anna Reynard
}

Key words: Latin, Greek, Primary School, Secondary School, Multi-Academy Trust, Mythology

We are now in our second year of Latin teaching at Lionheart Trust ${ }^{1}$ and it's fair to say that it has grown substantially as an initiative. The idea to teach Latin as an extra-curricular subject grew from our very positive experience of running Classics Clubs after school for Year 7s. These clubs were based on Greek and Roman mythology, local archaeology (plentiful given we are based in Leicester, a Roman city) and a little bit of Latin. The children loved all of these experiences and we realised quite quickly that there was an appetite for greater Latin teaching.

I was very fortunate that across the trust I had three teachers who had both the experience of learning Latin themselves and a desire to expand their teaching beyond their current subject and so were willing to teach some Latin themselves. At this point Lidia Kuhivchek - the Classics ambassador for Lionheart Trust - and I sat down to consider what we could offer the children and decided that it was perfectly viable to deliver Entry Level Latin ${ }^{2}$ as an after-school club for Year 8s, so that was what we did. We also took advantage of all the training available and Lucinda Cockerill and Lidia attended the Latin training offered by the charity Classics for $\mathrm{All}^{3}$ at their Summer School based in Harrow School and we successfully pitched for donated second-hand Cambridge Latin Course text books for the students. We ran the club in the academic year 2018 -2019 from two sites: Martin High School and Beauchamp College. Children also attended from three other Lionheart schools via transport paid for by Classics for All. It was a huge success. All the children passed the examination, we had excellent retention rates for the children across the year, and the teachers loved it. We also had winning entries in the East Midlands Association of Classical Teachers Latin Reading Competition $^{4}$ and although it was only ever intended to be a oneyear course, we had parents and children asking to do 'more Latin'. In the academic year 2019 - 2020 our Latin provision grew and we now teach Latin from three sites with Sally Woods delivering a course at Sir Jonathan North Academy and both Sally and a teacher from Judgemeadow Community College - Yasmin Musse - attending the Harrow training in September 2019. We again entered the Latin Reading Competition with three winning

Author of correspondence: Anna Reynard, E-mail: reynardanna@gmail.com

Cite this article: Reynard A (2020). Classics at Lionheart Trust. The Journal of Classics Teaching 21, 84-85. https://doi.org/10.1017/S2058631020000100 groups and are on track for four sites teaching Latin in academic year 2020 - 2021 when Yasmin (who has shadowed Lidia this year) will deliver at Judgemeadow Community College. The children have loved learning Latin. They recognise that it is unusual for state-school children and they are quite open about how special it makes them feel. It also gives them an identity within the school - they are Classicists and they embrace that. They wear little Classicist badges and they have spoken Latin in assembly and worked with their teachers to actively recruit next year's cohort. It's been wonderfully enriching for all involved.

With the success of the secondary forays into Latin, I wanted to see what we could do with the primaries. We had huge support from Leicester University in terms of training and advice and Lidia was keen to develop her skill set into key stage 2 . We pitched to Classics for All for funding to release Lidia from a day's teaching at Beauchamp College so we could offer a programme of study to the primaries. Once that funding was successful, we met with the primary heads and suggested a route forward. It was decided that Lidia would deliver Hands-Up Latin Primary Latin ${ }^{5}$ to children for one hour a week across Year 3 while the class teacher learned the basic Latin at the same time in preparation to deliver the content themselves the following academic year, when Lidia would go into year 4 and so on. This meant that we could both develop a generation of young children who had sustained exposure to Latin but (perhaps even more significantly) we could develop a number of primary staff who were trained to teach the language. Like the secondary project, it has been an enormous success with staff, parents and children. The children learn about the Romans in Year 3 anyway so the Latin beautifully complements this unit and the children have shown great aptitude for picking up the language and applying their understanding of it to their topic work. As with the secondary team, the teachers have also felt invigorated by this addition to their subject knowledge. Indeed, one of the Year 3 teachers is relocating to another position at the end of the year and was told at her recent successful job interview that her ability to teach Latin gave her the edge over the other candidates and she has been asked to deliver it in her new location too. In my experience this sums up my experience of Latin beautifully. It is infectious. Once it has a foothold in a school, it grows rapidly.

In my mind, for those looking to launch Latin in a state school, the hardest part is getting started. Leaders and teachers 
are reluctant (more so than students we found) and some of the old clichés rear up: 'It's a dead language, 'What's the point?' and 'Isn't it just for kids at Eton?' Once you have convinced your staff body to give it a go, the Latin itself does the talking. Everyone involved has commented on how different studying Latin is to studying any modern foreign language. In state schools anyway, it feels fresh and exciting, an opportunity and a gift, and the subject itself is far more wide-reaching. The resources focus on culture, history, religion, society, literature, music, drama. The students become fascinated by a whole world rather than just a language. Latin also offers schools the opportunity to be demographically and geographically relevant. Our Latin at both primary and secondary is designed around Roman Leicester and our children are fascinated to learn that Roman Leicester was as multicultural as millennial Leicester is and were tickled by the knowledge of a specifically Leicester-based Roman God. They have had so much fun writing curse tablets, looking at maps and tracking how Latin has evolved and contributed to the language we speak today. At Lionheart, we won't look back. We recognise what a wonderful opportunity studying Latin is for staff and students alike and we are committed to ensuring it remains an opportunity for our children.

\section{Notes}

1 The Lionheart Academies Trust is a family of eleven schools based in and around Leicestershire. For details of the Lionheart Trust, see https://www.lionhearttrust.org.uk/

2 Entry level Latin is a national qualification offered by the OCR examinations board. For details, see https://www.ocr.org.uk/qualifications/entry-level/latinr447-from-2016/

3 Classics For All is a charity which raises funds to enable schools, many in areas of high deprivation, to study Latin, Ancient History, Classical Civilisation and Ancient Greek. They offer funding to both primary and secondary schools across the UK, often to launch Classics for the first time. For details, see https://classicsforall.org.uk/ 4 The East Midlands Association of Classical Teachers exists primarily to connect teachers of Classical subjects throughout the East Midlands with each other. For details, see https://emact.wordpress.com/

5 Hands Up Education is a not for profit organisation and international community of practice, creating and sharing high quality teaching resources. The core focus of their work is on Latin and Classics for a modern curriculum. For details, see https://hands-up-education.org/primarylatin.html 